\title{
Diversas interpretaciones de una misma imagen: controversias iconográficas de santa Librada en el sureste peninsular dentro de un conjunto escultórico del siglo XVIII
}

\author{
Different interpretations for the same image: iconographic \\ controversies around saint Librada in a sculptural group in \\ south east Spain from $18^{\text {th }}$ century
}

Alejandro JAQUERO ESPARCIA

Universidad de Castilla-La Mancha

Recibido: 03/V/2018

Aceptado: 8/VI/2018

RESUMEN: La particular iconografía representada en la imagen de santa Librada la hace partícipe de un grupo de figuras religiosas con un rasgo muy característico: el elemento de la cruz como símbolo del martirio. Lo que puede parecernos un claro rasgo identificativo, en ocasiones consigue generar ciertas confusiones interpretativas. No se debe limitar el estudio concreto de una imagen a la simple valoración iconográfica de la misma. En estas líneas abordaremos un ejemplo derivado de las acciones de mecenazgo y patrocinio desarrolladas durante el mandato del cardenal Belluga en la antigua diócesis de Cartagena. Pretendemos analizar y emitir una relectura de un conjunto escultórico de mediados del siglo XVIII en el que, en principio, hallamos una representación de santa Librada junto a otro elenco de santas que no han sido todavía reconocidas.

Palabras clave: santa Librada; Cruz; Iconografía cristiana; Hagiografía; Cardenal Belluga

ABSTRACT: The particular iconography found on the tradition Saint Librada belongs to makes her a participant of a series of religious figures with a very specific characteristic: the cross symbolizing the martyrdom. However, this can lead to confusions when interpreting its meaning. An accurate analysis of the image cannot be only concerned with the assessment of its iconography. The aim and goal of this article is to study an example developed in the ancient Diocese of Cartagena under the bishopric of Cardinal Belluga. It is our goal to analyze and to re-evaluate of an sculpture set from the mid-1700s in which Saint Librada seems to appear along with other female saints still unrecognized.

Keywords: Saint Librada; Cross; Christian Iconography; Hagiography; Cardinal Belluga

La mayor dificultad que se plantea a la hora de abordar un estudio iconográfico es su interpretación completa y contextualiza$\mathrm{da}^{1}$. Son muchos los problemas que rodean

\footnotetext{
${ }^{1}$ El presente artículo se ha elaborado en el marco del grupo de investigación consolidado LyA (Estudios interdisciplinares de Literatura y Arte) de la Universidad
}

la correcta lectura de una imagen concreta, destacando entre ellos la caída en el olvido de su historia y la alteración o evolución de

de Castilla-La Mancha. Quisiera agradecer a Diego Lucendo Díaz su trabajo para obtener las fotografías de la cúpula y al Dr. Fernando González Moreno sus precisiones iconográficas sobre el tema. 


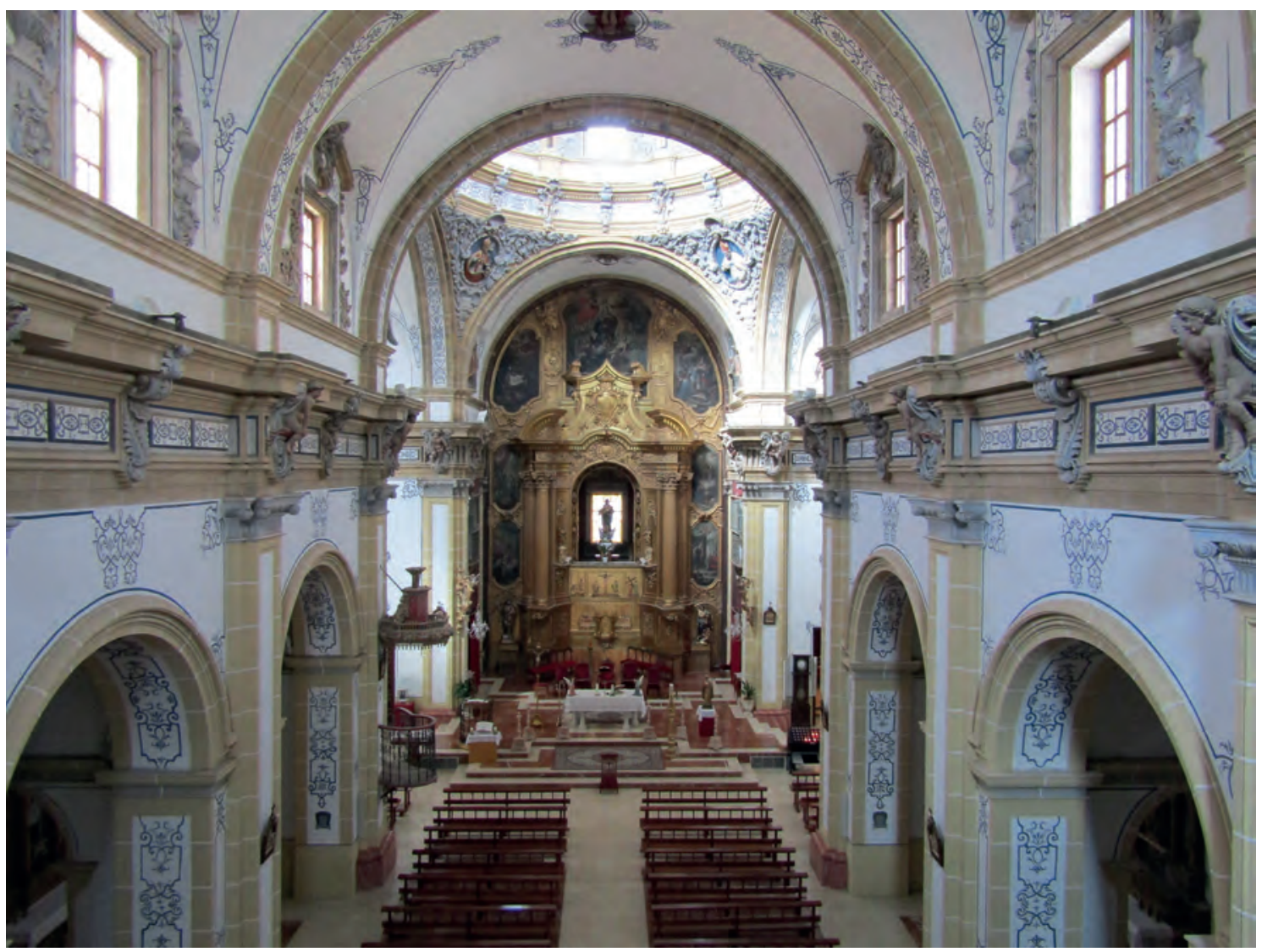

- Fig. 1. Interior de la Parroquia de Nuestra Señora de la Esperanza. 1716-1746. Peñas de San Pedro, Albacete. Fuente: foto del autor.

su significado 2 . No podemos pasar por alto el debate metodológico sobre el enfoque del estudio, es decir, la interpretación correcta y el buen uso de las herramientas iconográficas e iconológicas en el análisis de las imágenes $^{3}$. También juega un papel fundamental la problemática de las fuentes -escritas u orales- que permiten sustentar el significado de aquella iconografía. El origen de la inmensa parte de la cultura visual perteneciente al arte cristiano ha surgido, la mayoría de las veces, de la asimilación de formas pretéritas devocionales de otras culturas, la leyenda y la tradición. A todo ello hemos de sumar que una imagen concreta evoluciona de diverso modo según el contexto cultural en el que se

${ }^{2}$ E. PANOFSKY, Estudios sobre iconología, Madrid, 2008, pp. 21-26.

${ }^{3}$ R. GARCÍA MAHÍQUES, Iconografía e iconología. Volumen 1: La Historia del Arte como Historia Cultural, Madrid, 2008, pp. 20-30. desarrolla ${ }^{4}$. Pese a que esas figuras compartan unos valores comunes, no suelen mantener una unidad en su discurso, ampliándose las múltiples adaptaciones y asimilaciones de una imagen; en muchos casos, la realidad sociocultural concreta de un territorio determina la evolución de dicha imagen, añadiendo una mayor complejidad a su lectura ${ }^{5}$.

En estas líneas planteamos nuevas deducciones sobre un tema iconográfico. Comprendiendo la dificultad propia de estos estudios y ahondando en los mismos, analizaremos una posible representación de la imagen de santa Librada. Hablamos de posibilidad a la hora de definir la presencia de esta santa por los inconvenientes interpretativos de la imagen en cuestión. Dicha representa-

${ }^{4}$ E. H. GOMBRICH, La evidencia de las imágenes, Vitoria-Gasteiz, 2016, pp. 74-131.

${ }^{5}$ E. PANOFSKY, El significado de las artes visuales, Madrid, 1983, pp. 22-23. 


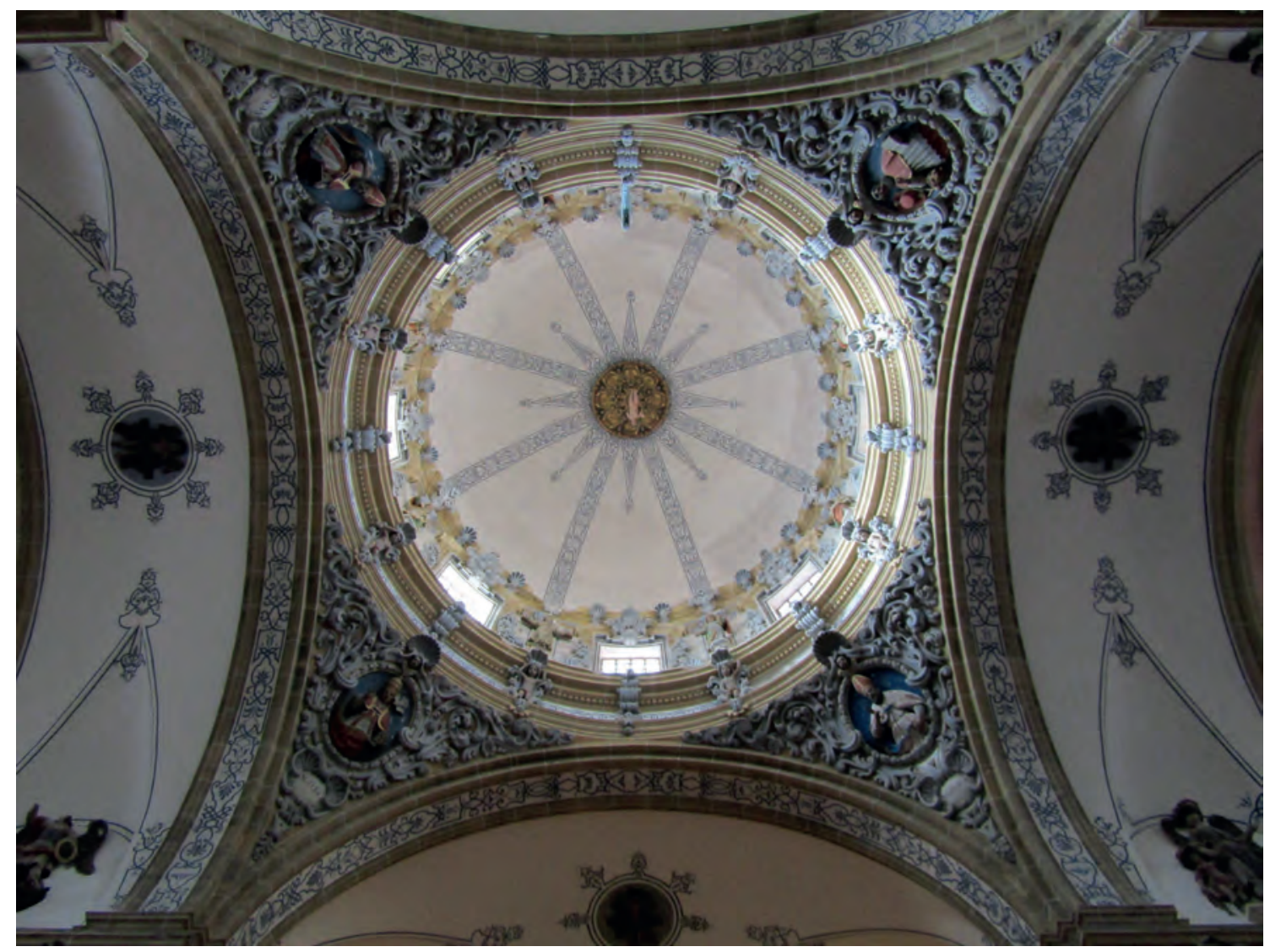

- Fig. 2. Atribuido a Cosme Carreras. Cúpula de la Parroquia de Nuestra Señora de la Esperanza. Ca. 1731. Peñas de San Pedro, Albacete. Fuente: foto del autor.

ción se halla acompañada por un conjunto escultórico que decora el tambor de la cúpula perteneciente a la Parroquia de Nuestra Señora de la Esperanza, en la localidad de Peñas de San Pedro (Albacete). El templo fue erigido durante la primera mitad del siglo XVIII, iniciándose su fábrica en el año 1718. La decoración del edificio está vinculada a la estética que la diócesis de Cartagena, auspiciada por los deseos del cardenal Belluga, decidió imponer durante el Setecientos en sus lugares de culto ${ }^{6}$ (Fig. 1).

${ }^{6} \mathrm{~J}$. RIVAS CARMONA, “Las iglesias barrocas de la ciudad de Murcia: consideraciones sobre su significación y arquitectura", Imafronte, no 19-20, 2007-2008, p. 398.
SOBRE EL CONJUNTO ESCULTÓRICO: PARTIENDO DE UN PRIMER ANÁLISIS FORMAL

Es necesario contextualizar el espacio con el fin de comprender de mejor manera la presencia de estas imágenes. Junto a la magnífica decoración de yeserías presente en el presbiterio y la nave principal del edificio, destaca su retablo mayor consagrado a la Virgen de la Esperanza, advocación principal del templo. Este se halla decorado por una serie de pinturas que narran hechos de la vida de la Virgen y coronado por la talla de la Virgen de la Esperanza elaborada por el escultor murciano Roque López ${ }^{7}$. Encua-

\footnotetext{
7 Han desaparecido otros dos retablos que estarían situados en los extremos de los brazos del transepto. El retablo principal ha sido estudiado en: L. G. GARCÍA-SAÚCO BELÉNDEZ, "El retablo mayor de Santa María de la Esperanza de Peñas de San Pedro", Al-Basit: Revista de estudios albacetenses, no 9, 1981, pp. 141-161; C.
} 
drada en el centro del discurso catequético que proponen la iconografía del retablo y los estucos, se nos presenta la decoración expuesta a debate: las ocho estatuas adosadas que se organizan alrededor del tambor que sustenta la cúpula de media naranja, de cuyo centro desciende una escultura de un niño o putto de considerables dimensiones (Fig. 2).

El grupo de estucos que sometemos a debate ha sido evaluado en un estudio anterior, por lo que sobre su interpretación ya existe una hipótesis. La interpretación pertenece al Dr. José Sánchez Ferrer, que revalorizó el conjunto y su valor discursivo. En su comentario, Sánchez Ferrer reconoce dos figuras principales: "santa Librada y santa Inés" ${ }^{8}$. Al conjunto se añaden las otras seis santas, cuya identificación no pudo averiguar, alegando la falta de símbolos iconográficos y la confusión que presentan algunos de ellos: aventura que una de ellas porta una "cabeza de dragón o tarasca", símbolo ambiguo adjudicable a "santa Perpetua, Marta, Juliana y Margarita". Estamos de acuerdo con el autor en que el espacio elegido para la escenificación del ciclo no es ni el más accesible ni el más visible para el espectador, lo que genera dificultades considerables, impidiendo una correcta lectura. No obstante, pensamos que debe primar la prudencia a la hora de emitir juicios descriptivos de este tipo, buscando evitar errores típicos como los que Gombrich señalaba en su colega Panofsky; un exceso de caudal visual por parte del investigador que llegue a generar el síntoma de la boa constructor ${ }^{9}$. Con una primera

PEÑA VELASCO, El retablo barroco en la antigua diócesis de Cartagena. 1670-1785, Murcia, 1992, pp. 407-408. Sobre la decoración interna del camarín que se articula con el retablo principal véase: J. SÁNCHEZ FERRER, "El camarín de la Virgen de la Esperanza en las Peñas de San Pedro", Al-Basit. Revista de estudios albacetenses, no 54,2009 , pp. 59-78.

${ }^{8}$ J. SÁNCHEZ FERRER, “Iconografía de los relieves de estuco de la Iglesia de la Esperanza de Peñas de San Pedro", Cultural Albacete, no 8, 2007, p. 14.

${ }^{9}$ C. MONTES SERRANO, "Et in Arcadia Ego. Panofsky en perspectiva", RA: revista de arquitectura, $\mathrm{n}^{\circ}$ 9, 2007, pp. 41-42. lectura a nivel iconográfico podemos presuponer que la imagen martirizada con la cruz podría ser santa Librada, pero ello implicaría descartar todos los demás casos de santas que también fueron crucificadas. Asimismo, es necesario aproximarnos al conocimiento de las otras figuras que conforman la composición del tambor, buscando su probable relación con la que, a priori, supone una lectura más clara.

Asimismo, no podemos ignorar los estudios referentes a la construcción del templo ni las fuentes primarias que recogen los procesos constructivos. Profundizando en las circunstancias en las que se generó esta obra y, de manera específica, en la decoración del tambor, advertimos la existencia de una separación estilística con el resto de los elementos iconográficos descritos. Todos los espacios de nueva manufactura generados durante la época del cardenal Belluga fueron sometidos al criterio estético y constructivo que buscó imponer en su territorio ${ }^{10}$. Así, en el caso de Peñas de San Pedro, al igual que en el de otros centros de la antigua diócesis de Cartagena, la aprobación del proyecto venía supeditada al estricto seguimiento de la normativa constructiva y ornamental impuesta por el cardenal. En el círculo de Belluga se encontraba Bartolomé de la Cruz Valdés -formado en el ámbito de Hurtado Izquierdo-, maestro que aprobó las trazas de la construcción. Como apuntó Sánchez Moreno, los criterios a seguir fueron presentados para ser seguidos fielmente por Pedro Ruiz Almagro, arquitecto que comenzó la construcción del templo bajo escritura firmada en el año $1717^{11}$.

Después del comienzo de la obra, hubo cambios generales en la dirección de la mis-

${ }^{10}$ E. HERNÁNDEZ ALBADALEJO, "Belluga y el mecenazgo eclesiástico", en C. BELDA NAVARRO (dir.) y J. GÓMEZ DE RUEDA (coord.), Luis Belluga y Moncada: la dignidad de la púrpura, Murcia, 2006, pp. 8385.

${ }^{11}$ J. SÁNCHEZ MORENO, “Notas sobre arquitectos en Murcia, y noticia del escultor Pedro Federico", Anales de la Universidad de Murcia, 1945-1946, p. 352. 
ma. Lamentablemente, no conservamos mucha documentación sobre el maestro decorador de estucos de este espacio arquitectóni$\mathrm{co}$, tanto por la falta de referencias al mismo en los libros de fábrica parroquiales como por la ausencia en el Archivo Catedralicio de Murcia. La obra se relaciona con los trabajos desempeñados por el cantero levantino Cosme Carreras, cuyo nombre aparece rotulado en uno de los muros del tambor, apuntándonos el año 1731 como la fecha de finalización del proyecto ${ }^{12}$. Durante estos años iniciales del siglo XVIII fue habitual perpetuar la tradición barroca en la que los mismos maestros de obra se encargaban o delegaban la ornamentación de los templos ${ }^{13}$. Sí que parece que dicha decoración del tambor, como han apuntado Belda Navarro y Hernández Albaladejo, fue motivo de disputa con el cabildo catedralicio murciano. Este organismo envió en el año 1739 a Jaime Bort en calidad de inspector, con el fin de agilizar la finalización del proyecto y controlar los excesos "en cosa superflua ni mas ornato y hermosura"14. De este modo, estos dos investigadores apuntan que las modificaciones que Cosme Carreras proponía con respecto a los demás elementos decorativos de las naves motivaron los enfrentamientos con Bort, dejando constancia de un conflicto de estilos.

La falta de documentación que nos asegure la interpretación correcta de las figuras nos obliga a recurrir a una lectura especifica de los elementos figurativos de la composición, pero partiendo de todos los supuestos. Proponemos un nuevo análisis de la iconografía de los ocho estucos, con la intención

\footnotetext{
${ }^{12}$ La inscripción es la siguiente: “ $\mathrm{M},{ }^{\mathrm{RO}}$ COSME CARRERAS / AÑO 1731 [Maestro Cosme Carreras, año $1731]^{\prime \prime}$

${ }^{13}$ P. GONZÁLEZ TORNEL, "El ornamento arquitectónico como base del cambio de gusto en la Valencia de mediados del siglo XVIII. De los estucos de la parroquia de San Andrés a los modelos académicos de Vicente Gascó en la capilla del Carmen", Ars Longa, no 20, 2011, p. 98.

${ }^{14}$ C. BELDA NAVARRO y E. HERNÁNDEZ ALBALADEJO, Arte en la región de Murcia: de la Reconquista a la Ilustración, Murcia, 2006, p. 326.
}

de definir las posibles identidades que aparecen en el tambor del templo de Peñas de San Pedro. Las imágenes más destacables y que mayores facilidades parecen presentar para su interpretación son las supuestas, según Sánchez Ferrer, santa Librada y santa Inés, pues portan atributos iconográficos "reconocibles". No obstante, antes de afirmar que los yesos hacen referencia a estas dos santas pensamos que cabe la posibilidad de añadir una serie de inconvenientes a esta interpretación. Es necesario, por lo tanto, proceder a una lectura más exhaustiva.

\section{LA IMAGEN DE SANTA LIBRADA}

Adosada a una de las pilastras que componen la cúpula y entre dos de los ocho ventanales -como se sitúan el resto de los estucos- se nos muestra una mujer crucificada mediante tres clavos y ataviada con una larga túnica decorada con motivos florales (Fig. 3). Esta le cubre el cuerpo por completo, dejando visibles pies y manos; la cabeza se encuentra decorada con una corona sustentada por unos pequeños ángeles, de los que al menos se conserva uno y la impronta de otro, desaparecido en la actualidad. No se ha escenificado un martirio muy severo, siendo escasos los restos de sangre en la composición; apenas se atisban mínimamente en una de las manos, mientras que los pies aparecen limpios. El rostro permanece sereno e inmutable. En definitiva, y tras las descripciones precedentes, todos los datos parecen apun-

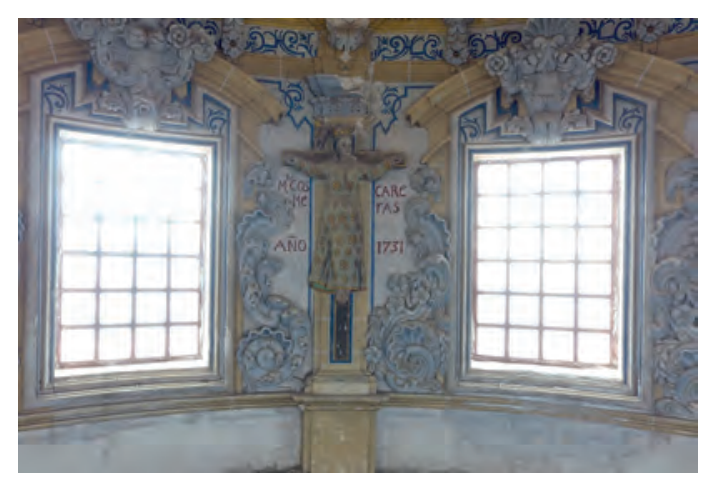

- Fig. 3. Anónimo. Santa Librada. Ca. 1731. Parroquia de Nuestra Señora de la Esperanza de Peñas de San Pedro, Albacete. Fuente: Diego Lucendo Díaz. 
tar a la presencia de santa Librada en esta zona de la cúpula. Ahora bien, no se puede verificar con totales garantías el que nos hallemos ante dicha santa por el mero hecho de que aparezca crucificada. La tarea que surge debe ser la de corroborar su iconografía específica. Debemos, por lo tanto, ahondar y conocer los orígenes de la iconografía de la santa para comprender si la representación que aparece está correctamente interpretada o estamos ante otra imagen.

En el santoral cristiano abundan ejemplos de mujeres martirizadas por medio de la cruz, aunque parezca una imagen atípica. Comprobamos este hecho de mejor manera a través de un grabado elaborado por Hieronimus Wierix sobre el tema iconográfico en cuestión, a principios del siglo XVII ${ }^{15}$. En la parte central de dicha estampa aparece la escena de la Pietà donde la Virgen sustenta el cuerpo fallecido de su hijo, acompañado de una sentencia bíblica del libro de Isaías; mientras, alrededor de la composición central se desarrolla una serie de diseños de otras ocho santas crucificadas: "Santa Marta y María, vírgenes; Santa Eulalia, virgen; Santa Tarbula, virgen; Santa Julia, virgen; Santa Blandina, virgen; Santa Febroma, virgen; Santa Firmina, virgen; Santa Wilgefortis, virgen" (Fig. 4). Esta escena invalida la idea de que automáticamente podamos asociar la imagen de una santa crucificada a la cultura visual de santa Librada, abriéndonos nuevas posibilidades $\mathrm{y}$, por ende, dificultando la interpretación de la imagen. Asimismo, llama la atención que ninguna de las crucificadas que aparecen en las escenas sea nuestra santa, pero sí se hace referencia a la que por mucho tiempo ha estado asociada a ella e influye en su evolución iconográfica, santa Wilgefortis.

En el diccionario iconográfico de Louis Réau observamos este detalle: la definición

${ }^{15}$ Forma parte de un conjunto de tres estampas de santos, santas y niños martirizados a través de la cruz. M. MAUQUOY-HENDRICX, Les stampes des Wierix conserves au cabinet des stampes de la Bibliotheque Royale Albert $I^{o}$, Brussels, 1978, T. II, pp. 187-189. de Librada nos remite a Wilgefortis, siendo una denominación más de aquella para el historiador del arte francés ${ }^{16}$. La narración de la hagiografía de santa Wilgefortis deja claro sus legendarios orígenes y las variadas vías de creación que permiten el surgimiento de esta virgen crucificada y barbada; no obstante, lo que más nos interesa destacar es la característica dada por Réau, la malformación hagiográfica: "Esta leyenda fabulosa es sólo una trama de tópicos hagiográficos. La historia de la "virgen fuerte" (porque es de esas dos palabras Virgo fortis que procede el curioso nombre de Wilgefortis), que habiendo elegido a Cristo como esposo pide a Dios que la afee o desfigure para que ningún hombre la pida en matrimonio [...] La génesis de esta leyenda es uno de los casos más curiosos y típicos de malformación hagiográfica, engendrada por una falsa interpretación de una imagen de devoción. El origen de la leyenda ha sido la propia iconografía mal comprendida"17.

Son pocos los datos sobre el tema iconográfico de Librada que no se encuentren impregnados de los sucesos propios de Wilgefortis. Como describe Réau, la santa pide su transformación con el fin de poder conservar su virginidad, consternando a los pretendientes que su padre le buscaba. Dicha transformación se produce mediante el crecimiento de la barba, que masculiniza la figura y la vuelve repulsiva frente a los hombres. El atributo de la barba sobre una deidad o figura de santidad femenina nos remite a herencias mitológicas que la tradición medieval ha reformulado. Concretamente, algunas imágenes antiguas de Afrodita la muestran con estos rasgos masculinos, destacando de manera prominente la barba e, incluso, sien-

${ }^{16}$ L. RÉAU, Iconografía del arte cristiano. Iconografía de los santos: de la $G$ a la O, Barcelona, 1997, p. 247. Esta confusión también la observamos en otros diccionarios iconográficos. Véase J. FERRANDO ROIG, Iconografía de los santos, Barcelona, 1991, p. 170.

${ }^{17} \mathrm{~L}$. RÉAU, Iconografía del arte cristiano. Iconografía de los santos: de la P a la Z, Barcelona, 1998, pp. 348-349. 


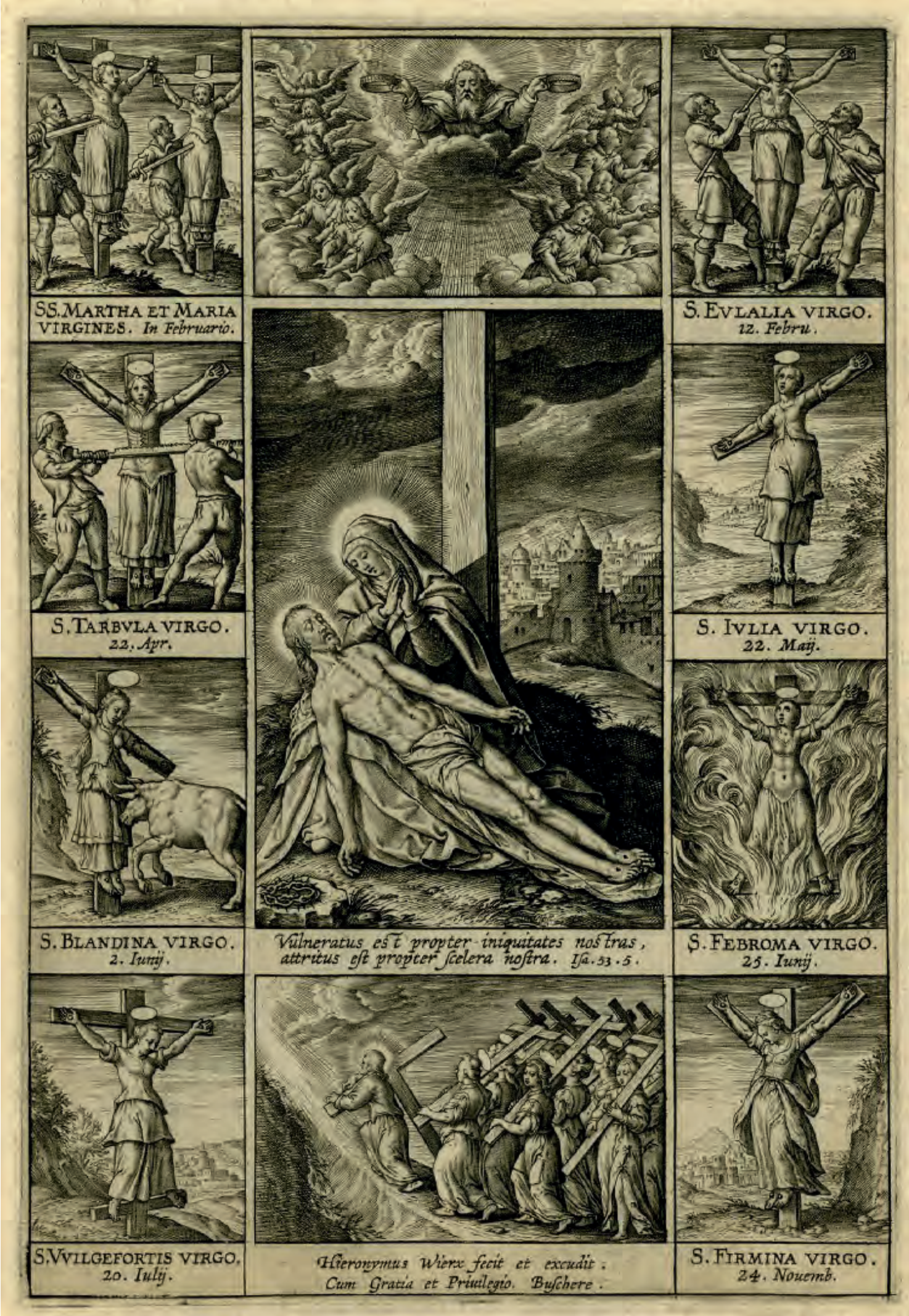

- Fig. 4. Hieronimus Wierix. Pietà con el crucificado rodeada de mártires. Ca. 1609. Grabado calcográfico, 16,1 x 10,3 cm. British Museum, Londres. Fuente: British Museum. 
do denominada como Afrodito ${ }^{18}$. A su vez, los orígenes de esta iconografía los podemos encontrar en tradiciones culturales orientales, asimiladas y adaptadas por los griegos ${ }^{19}$. Retomando la narración, en respuesta a la afrenta que le plantea su hija, su padre decide crucificarla, para que sufra el mismo martirio que a la persona que ama. A la narración general de la historia de la santa se han de añadir las particularidades propias de cada región, que fueron planteando sucesivos cambios tanto en el nombre como en la iconografía de la santa. Sirva de ejemplo el tríptico creado sobre la santa por Hyeronimus Bosch elaborado en los Países Bajos y destinado a Venecia, donde nos la presenta crucificada, pero sin barba ${ }^{20}$.

En realidad, analizando las vidas de ambas santas no hallamos los suficientes paralelismos como para que se produzcan malinterpretaciones; los martirios sufridos por cada una de ellas son diferentes, partiendo de las fuentes con las que contamos. Para conocer el influjo de una con respecto a la otra hemos de hacer un breve inciso exponiendo las fuentes hagiográficas propias de Librada, con el fin de entender mejor el origen de la santa. En el territorio europeo e inmersos en plena Edad Media, no hallamos ninguna descripción sobre su vida en $\mathrm{La}$ Leyenda Dorada de Santiago de la Vorágine, verdadero referente para el mundo artístico medieval; tampoco obtenemos resultados siglos más tarde ni en las Actas de Mártires ni en el Martirologio Romano ${ }^{21}$. Se ha de centrar el análisis en fuentes de menor alcance, focalizando la atención en el entorno de la

\footnotetext{
${ }^{18}$ C. GARCÍA GUAL, Introducción a la mitología griega, Madrid, 2013, p. 145.

${ }^{19}$ A. H. KRAPPE, “The Bearded Venus", Folklore, $\mathrm{n}^{\circ}$ 56, 1945, pp. 333-334.

${ }^{20}$ L. J. SLATKES, "Hyeronymus Bosch and Italy", The Art Bulletin, $\mathrm{n}^{\mathrm{0}}$ 57/3, 1975, pp. 335-345.

${ }^{21}$ M. E. DÍAZ TENA, "La vida de Santa Librada y su fuente medieval", Culturas Populares. Revista Electrónica (en línea), no 8, 2009, consultado el 25 de febrero de 2017. URL: http://dspace.uah.es/dspace/ handle/10017/19820?locale-attribute $=\mathrm{es}$
}

diócesis de Sigüenza. Dentro del contexto hispano, hallamos los primeros datos sobre nuestra santa en un Breviario del siglo XII, vinculado a dicho obispado ${ }^{22}$. Como ya indicó en su momento Martínez Gómez-Gordo, "este Leccionario constituye el documento seguntino sobre la santa más antiguo conocido hasta el presente"23.

No será hasta después de Trento y ya finales del siglo XVI cuando hallemos algunos ejemplos dentro de varios Flos Sanctorum como el de Pedro de la Vega - el autor la incluye dentro de las vidas de santos extravagantes- (1580) o el del padre Alonso de Villegas (1588), junto a otras referencias literarias desde el campo de la poesía o el teatro de las que ya existen diferentes trabajos ${ }^{24}$. Los elementos más importantes surgidos en dichas narraciones y que influirán en la iconografía de Librada -partiendo de lo expuesto en el Breviario del siglo XII- serán la narración de su nacimiento, en el que se la vincula a ocho hermanas más surgidas del mismo parto, $\mathrm{y}$ la versión de su martirio, en la que se explica la decapitación. Todos estos datos nos presentan una iconografía bien diferente de la actual, por lo que hubo de acontecer un cambio drástico en la concepción de la imagen de la santa.

Villegas advierte ya la devoción que se le procesa en el ámbito del obispado de Sigüenza y en su catedral ${ }^{25}$. Fruto de la admiración que aparenta despertar entre las

22 J. CARMONA MUELA, Iconografía de los santos, Madrid, 2011, p. 280.

${ }^{23}$ J. A. MARTÍNEZ GÓMEZ-GORDO, “Santa Librada, virgen y mártir (revisión de su hagiografía, iconografía y culto)", Anales seguntinos, nº 12, 1996, p. 12.

${ }^{24}$ P. VEGA, Flos sanctorum, Sevilla, 1580, T. II, fols. 279v.-280v.; A. VILLEGAS, Flos sanctorum y Historia general de la vida y hechos de Iesuchristo, Madrid, 1588, fols. $51 \mathrm{v} .-52 \mathrm{r}$.

25 "En la Iglesia de Sigüenza se tiene en gran veneracion el cuerpo de santa Liberata, que mudando algo el nombre, se pronuncia comúnmente Librada. Tiene allí esta santa un grande y riquísimo sepulcro de diversos jaspes, que debe ser una de las mas sumptuosas obras que en sepulchro ay en España". A. VILLEGAS, Op. cit., fol. 51v. 
gentes de ese territorio surge a principios del siglo XVII una apología de santa Librada a cargo de Baltasar Porreño, cura de las villas de Sacedón y Córcoles y visitador general del obispado de Sigüenza. En su Discurso de la vida, y martirio de la gloriosa virgen y mártir Santa Librada, impreso en el año 1629, se abordan muchos aspectos de la vida, martirio y culto de la misma. Entre las muchas luces y aclaraciones dadas por el autor, se nos explica el origen de las relaciones de Librada con España, habiendo nacido ella en una zona gallego-portuguesa ${ }^{26}$. En la leyenda se narra como la madre de la santa dio a luz a ella y a otras ocho hermanas; el parto tan numeroso fue comprendido como un mal presagio divino, por lo que la madre, por miedo a las represalias de su marido, decide abandonarlas en manos de unas campesinas cristianas. Estas por su parte deciden bautizar a las niñas: "Recibieron las amas Christianas las niñas con mucho agrado, y las hizieron baptizar, poniéndole a cada una su nombre, esto es. Librada por aver sido libre de las aguas, también fue llamada Vuilgefortis, o Virgo fortis por su gran valor, y fortaleza; Genivera, o Genevera a quien obedecían todas las hermanas; Victoria; Eumelia o Eufemia; Germana; Gema, o Marina; Marcia, o Marciana; Basilia; Quiteria"27.

Asistimos aquí a un hito en la evolución de la iconografía de santa Librada, pues el autor establece una relación entre el nombre de Librada y Wilgefortis que marcará el inicio de la confusión entre ambas historias e iconografías ${ }^{28}$. Igualmente interesa la narración del martirio. Las hermanas deciden separarse tras el encuentro con su padre, que las amenaza con la muerte si no abandonan el catolicismo. Por sí mismas deciden huir del reino para practicar de manera libre su fe; comprenden el riesgo que ello conlle-

${ }^{26}$ B. PORREÑO, Discurso de la vida y martirio de la gloriosa virgen y mártir Santa Librada, Cuenca, 1629, fol. $14 \mathrm{v}$.

\footnotetext{
${ }^{27}$ Ibídem, fol. 20v.

${ }^{28}$ J. A. MARTÍNEZ GÓMEZ-GORDO, Op. cit., pp. 17-22.
}

va y, además, no quieren terminar siendo martirizadas por su propio padre. Tras estos sucesos, todas ellas fueron perseguidas, capturadas y martirizadas. En su martirio sufrieron la decapitación; sin embargo, en la narración de Porreño surge una importante modificación, puesto que Librada padece la crucifixión: "Viendo pues el tirano que no solamente no se rendia Librada, antes dava aliento a los demás, se determino a darle muerte de Cruz, pareciéndole que desta manera le dava mayor tomento y afrenta [...] Estava el cuerpo vestido de una túnica por la honestidad, el qual quedo hermoso como el Sol, y el alma bolo al cielo a ser coronada de gloria" 29 .

El autor altera de forma deliberada el martirio de santa Librada, aun habiendo utilizado como base de su estudio los martirologios anteriormente nombrados. De este modo, en la leyenda se definen por una parte su relación con otra serie de santas, las hermanas de ella, y por otra se asimila el martirio propio de Wilgefortis; las características y paralelismos existentes entre estas dos figuras terminan haciendo que Librada adopte una iconografía mucho más distintiva que la de sus hermanas. La obra del religioso seguntino es una muestra de la evolución que, de manera paulatina, se iba a ir desarrollando en las representaciones figurativas de la santa, teniendo su punto de inflexión a comienzos del siglo XVII. Ejemplo de la evolución iconográfica de Librada en el mundo artístico fue la propia capilla de la catedral de Sigüenza: hallamos como herencia del siglo XVI las tablas que decoran el retablo por mano de Juan Soreda en las que aparecen Librada y sus hermanas, junto a escenas del martirio por degollación de la misma ${ }^{30}$; no obstante, en el año 1694 fue co-

${ }^{29}$ B. PORREÑO, Op. cit., fols. 35r.-35v.

${ }^{30} \mathrm{El}$ profesor Angulo destacó la conexión con la antigüedad clásica de estas tablas, en las que aparecen para reforzar la idea de la fortaleza en la fe escenas mitológicas del ciclo de Hércules. D. ANGULO ÍÑIGUEZ, La mitología y el arte español del Renacimiento, Madrid, 1952, p. 89. Un trabajo más pormenorizado sobre el tema en A. ÁVILA, Imágenes y símbolos en la arquitectura pintada 
locada ocultando esta tabla una escultura de la santa con la cruz, su nueva interpretación, que para los doctos y seguidores de la literatura sagrada donde aparecían los sucesos originales y no alterados de su hagiografía fue un gran escándalo.

Los autores que no conocían en profundidad la iconografía de santa Librada se limitan a describir la existencia de una serie de esculturas y pinturas referentes a ella, como es el caso de Antonio Ponz en su Viage de España, a finales del siglo XVIII ${ }^{31}$. A comienzos del siglo XIX se publica otra obra hagiográfica sobre ésta por Diego Eugenio González Chantos y Ullauri, también en Sigüenza. En ella critica el trabajo de exégesis elaborado por Porreño; sobre todo incide en la incorrecta vinculación que hace de Librada con Wilgefortis: "Si tan persuadidos quedaron de que Santa Librada era también Wilgeforte, y de que su martirio fue en el 20 de Julio, en virtud de lo qual trasladaron en el instante á dicho dia su solemnidad, y pusieron delante de su Altar antiguo postiza una Santa crucificada; ¿no es también de admirar mucho que dexasen entonces la tabla del medio de las pinturas del dicho Altar antiguo, de la que se representa la Imagen en la misma disposicion en la que por tantos siglos la estuvo venerando y celebrando esta Iglesia en 18 de enero, capitis abscissione?. Pues de los dos modos y en el mismo altar se halla actualmente la imagen de la Santa" ${ }^{\prime 2}$.

A finales del Ochocientos, Manuel Pérez-Villamil en su descripción de la catedral de Sigüenza vuelve a incidir en la incorrecta iconografía: “Las pinturas son bastante buenas y aunque no contemporáneas del grandioso monumento, pertenecen indudablemente a fines del siglo XVI. Encima de estas pinturas aparecen hoy superpuestas la ima-

española (1470-1560), Barcelona, 1993, pp. 179-187.

${ }^{31}$ A. PONZ, Viage de España, o Cartas en que se da noticia de las cosas más apreciables y dignas de saberse, que hay en ella, Madrid, 1788, T. XIII, p. 14.

${ }^{32}$ D. E. GONZÁLEZ CHANTOS Y ULLAURI, Santa Librada. Virgen y mártir, patrona de la Santa Iglesia, ciudad y obispado de Sigüenza, Madrid, 1806, p. 104. gen crucificada de la Santa, cuya escultura, de escaso mérito, fue colocada en el año 1694 [...] Santa Librada murió decapitada, capitis abscissione martyrium consummavit, según dicen las antiguas lecciones del Breviario del siglo XVII. Lo de la crucifixión fue cosa del siglo XVII, por efecto de confusión de nombres y prurito de decir novedades, sin que lo autorice ningún antiguo monumento" ${ }^{\prime 3}$.

Merece ser destacado el que desde el mundo de la teoría artística no se planteasen soluciones para los artífices a la hora de representar dicha iconografía. Francisco Pacheco en las adiciones a imágenes religiosas que introduce al final de su Arte de la Pintura no comenta nada sobre santa Librada ${ }^{34}$; tampoco hallamos los consejos pertinentes a la descripción de la imagen en el posterior trabajo y síntesis del ideario barroco elaborado por Juan Interián de Ayala, el Pictor Christianus Eruditus, ya inmerso en el siglo XVIII. El silencio desde el campo de las fuentes escritas del Siglo de Oro hizo que los ejemplos artísticos, unidos a la deliberada malinterpretación de las fuentes hagiográficas, se impusiesen en su modificación iconográfica ${ }^{35}$; la adaptación de la cruz al martirio generó una imagen que sí tuvo acogida en la cultura visual de la población.

${ }^{33}$ M. PÉREZ-VILLAMIL, La catedral de Sigüenza, Madrid, 1899, pp. 300-301.

\footnotetext{
${ }^{34}$ Parece algo comprensible por no ser aquella una imagen con excesiva devoción, limitándose el tratadista sevillano a describir imágenes de mayor devoción y desarrollar otros problemas iconográficos. Véase B. BASSEGODA I HUGAS, “Observaciones sobre el Arte de la Pintura de Francisco Pacheco como tratado de iconografía", Cuadernos de arte e iconografía, T. II, nº 3, 1989, pp. 185-196.

${ }^{35}$ La influencia de las ideas religiosas en la teoría artística española del siglo XVII fue palpable en la concepción de la obra de arte y en los propios artistas. Nos parece curioso que no se haga ninguna mención sobre santa Librada en los diversos ejemplos literarios que ofrece la época. J. PORTÚS PÉREZ, “Tratados de pintura y tratados de imágenes sagradas en la España del Siglo de Oro", en J. RIELLO (ed.), Sacar de la sombra lumbre... La teoría de la pintura en el Siglo de Oro (1560-1724), Madrid, 2012, pp. 21-31.
} 
Pese a que, tras los datos expuestos, ya hablamos de Librada como una martirizada por crucifixión, se pueden continuar añadiendo supuestos que han motivado ciertas confusiones en estudios similares. En la misma época en la que se confecciona el ciclo del municipio albaceteño ya circulan estampas con la nueva iconografía de la santa que facilitan su asimilación por parte del espectador. Sirve como magnífico ejemplo el grabado calcográfico elaborado por Manuel Salvador Carmona en 1766 (Fig. 5) ${ }^{36}$; la talla que inspira el diseño de este grabado a buril corresponde a su tío, Luis Salvador Carmona. Si observamos la inscripción de la estampa podemos leer "Santa Librada. Patrona del Obispado de Sigüenza, que se venera en la Parroquia de S. Justo y Pastor de Madrid", haciendo referencia a la ubicación de la es-

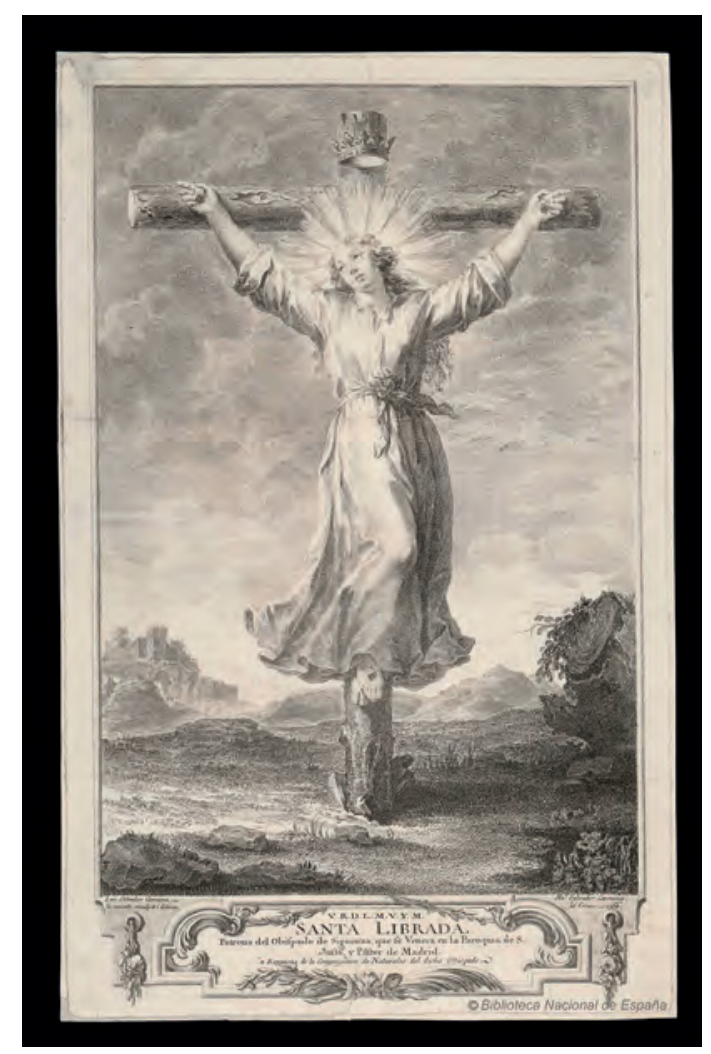

- Fig. 5. Manuel Salvador Carmona. Santa Librada. 1756. Grabado calcográfico. Biblioteca Nacional de España, Madrid. Fuente: Biblioteca Nacional de Madrid.

${ }^{36}$ A. GALLEGO, Historia del grabado en España, Madrid, 1979, pp. 280-283. cultura, actual Basílica Pontificia de San Miguel.

Sabemos que en el Museo Nacional de Escultura de Valladolid se encuentra una talla casi idéntica de Luis Salvador Carmona. Esta imagen de crucificada hoy en día se reconoce como santa Eulalia de Mérida, pese a los paralelismos que existen con aquella y la Librada reproducida en el grabado anterior (Fig. 6).

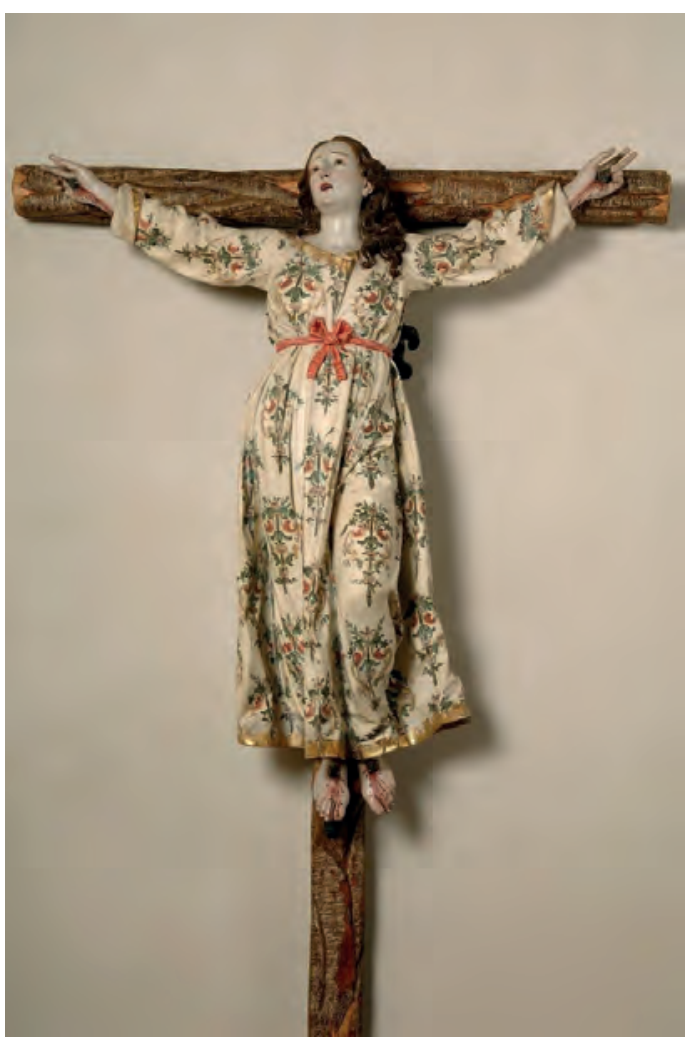

- Fig. 6. Luis Salvador Carmona. Santa Eulalia de Mérida. Ca. 1760. Museo Nacional de Escultura, Valladolid. Fuente: Museo Nacional de Escultura.

La descripción fue formulada por el profesor Urrea Fernández, que en un primer momento consideraba a la imagen de Valladolid otra interpretación de santa Librada por parte de Carmona ${ }^{37}$. Sin embargo, en posteriores investigaciones revisó su comentario, concretando la presencia de santa Eu-

37 J. URREA FERNÁNDEZ, "Revisión a la vida y obra de Luis Salvador Carmona", Boletín del Seminario de Estudios de Arte y Arqueología, no 49, 1983, p. 446. 
lalia, ya que la imagen procedía del extinto convento vallisoletano de Nuestra Señora de la Merced, donde se situaría junto a otra talla de San Dimas en los altares colaterales del recinto $^{38}$. Todas estas complejidades interpretativas nos sirven como otro argumento más de los intrincados límites iconográficos en los que se mueve Librada; una serie de continuas variaciones iconográficas resultado de incorrectas lecturas de su hagiografía hechas por autores como Porreño.

\section{EL CONJUNTO ESCULTÓRICO: HA- CIA UNA LECTURA DE CONJUNTO}

Tras lo expuesto anteriormente y con la justificación teórica de dicha iconografía, podemos personificar en el relieve de Peñas de San Pedro a la figura de santa Librada, pretendiendo a través de esta imagen dar mayor claridad interpretativa a los otros relieves del tambor. Para ello, procedemos ahora a describir otra de las figuras significativas de este conjunto y que, a nuestro parecer, puede dotar de mayor sentido al grupo es-

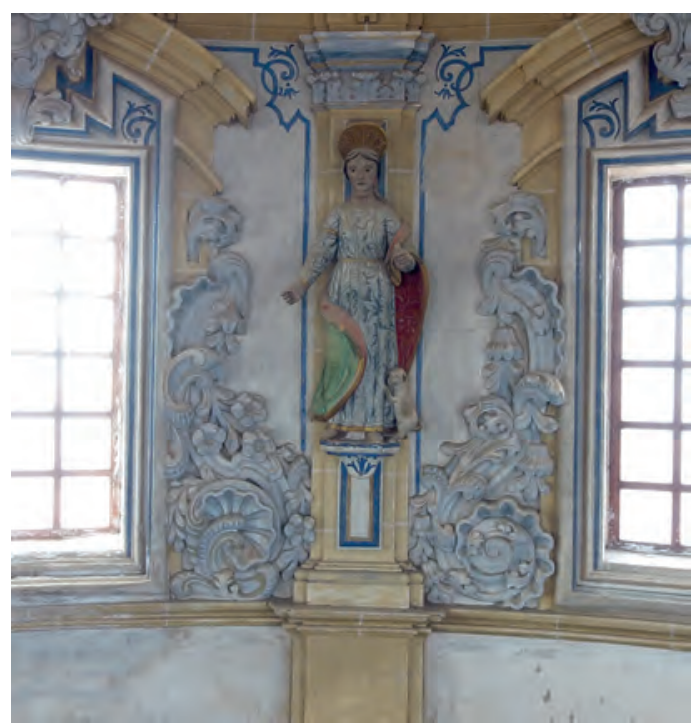

- Fig. 7. Anónimo. Santa Quiteria. Ca. 1731. Parroquia de Nuestra Señora de la Esperanza de Peñas de San Pedro, Albacete. Fuente: Diego Lucendo Díaz.

${ }^{38}$ J. URREA FERNÁNDEZ, "Santa Eulalia", en M. ARIAS MARTÍNEZ (coord.), Tesoros del Museo Nacional de Escultura "Catálogo de la exposición", Zaragoza, 2005, pp. 151-152. cultórico. Atendemos al estuco definido por Sánchez Ferrer como "santa Inés" (Fig. 7).

Al lado de Librada observamos la figura de una doncella vestida con una túnica azul. La decoración está compuesta por motivos florales, y a la vez aparece cubierta por otro manto verde al exterior y rojo en su interior, con los bordes dorados. Destaca en el busto un claro signo martirial: surge un corte que cruza horizontalmente el cuello de la santa, del que manan unas gotas de sangre, pero sin destacar la severidad del acto. La cabeza se exhibe coronada por un nimbo y en una de sus manos se aprecia lo que algún día pudo haber sido una palma del martirio, de la que solo queda el inicio de aquella. El símbolo más característico y que la diferencia de las demás esculturas que aparecen en la cúpula, con las que comparte los rasgos martiriales descritos, es el animal que permanece con ella, levantado junto a una de sus piernas. Sánchez Ferrer lo describe como un cordero $\mathrm{y}$, por tanto, justifica que la figura del tambor sea una imagen de santa Inés ${ }^{39}$; sin embargo, nosotros pensamos que esto es un error. Observando mejor la imagen vemos que el pequeño animal simbolizado es un perro $y$, por lo tanto, la atribución iconográfica anterior no es válida. Debemos, por lo tanto, modificar la descripción de esta imagen para amoldarla a los patrones iconográficos de santas que, como atributo particular, portasen este tipo de animal. Buscando una imagen en relación con la primera que ya hemos identificado surge la de santa Quiteria. A continuación, desarrollaremos los argumentos en los que sustentamos nuestra hipótesis.

El primer aspecto que debemos destacar es que la forma en la que esta escultura aparece ejecutada encaja con la de la santa propuesta; el martirio por decapitación se simboliza a través de la marca en el cuello que consta en el estuco ${ }^{40}$. En las narraciones de la muerte de Librada que hemos visto se

\footnotetext{
${ }^{39}$ J. SÁNCHEZ FERRER, “Iconografía de los relieves...", p. 14.

${ }^{40}$ P. VEGA, Op. cit., T. II, fol. 102r.
} 
nos explica que todas sus hermanas fueron martirizadas mediante la degollación, por lo que esta característica justificaría su presencia y vinculación con el resto. Aunque otra de las manifestaciones de santa Quiteria es presentarla justo después de su martirio, con la cabeza recién cortada entre sus manos, no es extraño representarla de esta forma, además de acompañada de un perro ${ }^{41}$. Dicha iconografía está ligada a su figura por el carácter protector que se le atribuye: la curación de enfermedades rabiosas ${ }^{42}$. Entre las personalidades femeninas del santoral no encontramos muchas santas que se caracterizan por tener como atributo al perro, más bien se vincula este animal a otros santos de corte masculino, como san Roque, santo Domingo o san Wendelino. Una de las escasas imágenes que podrían encajar en el perfil es la de santa Margarita de Cortona, terciaria franciscana que se representa acompañada de su fiel compañero cánido ${ }^{43}$. Debemos descartar la presencia de dicha santa italiana por la nula relación con el contexto y la escena en la que se encuentra incorporada.

La presencia de santa Quiteria en el grupo de mártires abre nuevas posibilidades a la explicación general de los relieves. Las otras esculturas en las que también destacan los signos martiriales de la degollación permiten elucidar la sentencia de que nos encontramos ante una representación de santa Librada y sus hermanas, como en el ciclo de Sigüenza: Quiteria, la propia Librada, Genivera, Victoria, Eumelia, Germana, Gema, Marcia y Basilia; no obstante, nos faltaría un estuco para poder cerrar el conjunto de hermanas al completo. Pese a la ausencia de una

${ }^{41} \mathrm{~L}$. RÉAU, Iconografía del arte cristiano. Iconografía de los santos: de la G..., p. 113.

42 "De quien todos confiesan ser abogada contra el mal de rabia, sucedido de mordeduras de animales ponçoñosos que por ser esposa de IesuChristo, quiso su magestad darle este privilegio [...] Tambien están allí escritos muchos milagros en personas que ha librado Dios de grandes peligros, en especial de mordeduras de perros rabiosos, por averse encomendado a esta santa". A. VILLEGAS, Op. cit., fols. 18v. y 19v.

${ }^{43}$ J. FERRANDO ROIG, Op. cit., pp. 187-188. figura más en el espacio del tambor, achacable a la disposición y capacidad del espacio elegido, la asociación de estos estucos con el ciclo seguntino daría un significado correcto a la lectura de esta composición. Un examen correcto del mismo debe realizarse estudiando todas las obras en conjunto, buscando el mensaje iconológico que buscan transmitir.

Todas las imágenes fueron confeccionadas con una serie de elementos iconográficos y estilísticos en común que los caracteriza como un grupo unitario, de ahí la casi equivalente forma en sus rostros, los idénticos signos martiriales en los cuellos o las palmas del martirio. De igual modo y salvo en el caso de Librada, para cuya representación se ha optado por la iconografía alternativa surgida a principios del siglo XVII, las demás santas comparten el signo martirial de la degollación; así es como fueron martirizadas las hermanas de la erróneamente crucificada, como puede verse en los relatos hagiográficos utilizados. Al igual que en el ejemplo de la catedral de Sigüenza, las imágenes que pueden presentar una iconografía propia y distinta son Quiteria y Librada, una con el animal que personifica su patronato y la otra con el malinterpretado símbolo de su martirio. No debemos tampoco olvidar la presencia del niño o putto que se descuelga desde el centro de la cúpula y permanece en medio de las estatuas del tambor. Si retomamos el texto de Porreño, durante el castigo y la muerte de Librada, leemos que "Estava el cuerpo vestido de una túnica por la honestidad, el qual quedo hermoso como el Sol, y el alma bolo al cielo a ser coronada de gloria"44. En los demás relatos hagiográficos también se relata esta ascensión del alma hacia la gloria después de padecer el martirio; aferrados a su amor y fe a Cristo consiguen la redención por medio del castigo recibido. La figura del niño puede representar el alma de dicha santa -y la de sus hermanasascendiendo al cielo para recibir el premio merecido por su fe y esperanza en Cristo ${ }^{45}$.

\footnotetext{
${ }^{44}$ Véase nota 21.

45 “ $\mathrm{El}$ arte bizantino representaba el alma en forma
} 
La identificación del alma por medio de la figura de un niño fue una tipología utilizada con frecuencia en la iconografía cristiana del Barroco, teniendo sus orígenes en otras manifestaciones iconográficas de la Antigüedad y la Edad Media ${ }^{46}$.

A todo ello hemos de sumar la simbología propia que aporta la cantidad de figuras del tambor; el número ocho como símbolo ligado a la resurrección de Cristo ayudaría a comprender la imagen del niño o alma que asciende asistida por las santas ${ }^{47}$. Igualmente, debemos plantear la posibilidad de que el espacio haya sido configurado bajo una óptica de devoción mariana; se podría interpretar que los estucos responden a una nueva concepción y modernización de la iconografía de las "ocho mujeres fuertes" del Antiguo Testamento -Débora, Jael, María la profetisa, Sara, Abigail, Ruth, Esther y Judith-, pero en este caso las virtudes demostradas en las diferentes hagiografías de las santas hacen que ejerzan el rol principal, sustituyendo a las figuras bíblicas y argumentando la falta de una de ellas. El tema simbólico de las "mujeres fuertes" encuentra desarrollo teórico y práctico durante el siglo XVII ${ }^{48}$; como ejemplo de la pervivencia barroca a mediados del Siglo de las Luces nos sirve el camarín de la Virgen del monasterio de Guadalupe, deco-

de niño desnudo y sin alas, modelo que llegaría a consagrarse en Occidente". J. HALL, Diccionario de temas y símbolos artísticos, Madrid,1987, p. 33; J. E. CIRLOT, Diccionario de símbolos, Madrid, 1997, pp. 331-332.

${ }^{46}$ Tenemos ejemplos de la personificación del alma en niños en obras como la del Entierro del señor de Orgaz de El Greco, donde el alma que asciende protegida por un ángel se representa figurando de forma leve a un niño; también nos sirve, elaborado casi medio siglo después, el Cristo contemplado por el alma cristiana de Velázquez. Véase A. RODRÍGUEZ G. DE CEBALLOS, "Fuentes iconográficas y literarias del cuadro de Velázquez Cristo y el alma cristiana", Cuadernos de Arte e Iconografía, nº 8, 1991, pp. 82-90.

${ }^{47}$ J. CHEVALIER y A. GHEERBRANT, Diccionario de los símbolos, Barcelona, 1986, p. 769.

${ }^{48}$ E. BORNAY, Mujeres de la Biblia en la pintura del Barroco, Madrid, 1998, p. 28. rado alrededor del año 1732 con ocho esculturas pertenecientes a este ciclo ${ }^{49}$.

\section{CONCLUSIONES}

Nuestra intención principal ha sido la de aportar más herramientas que faciliten la exégesis de un ciclo concreto. Hemos partido de un estudio riguroso de las fuentes y los elementos iconológicos para plantear una nueva lectura de un conjunto escultórico que presentaba serios inconvenientes, sin descartar ninguna hipótesis interpretativa. Tras el análisis individualizado de la diversa iconografía, llegamos a la conclusión de que en el conjunto de ocho estucos de la localidad de Peñas de San Pedro observamos un ciclo de Librada, Quiteria y sus restantes hermanas. Por un lado, Quiteria es reconocible por las señales de su martirio y el animal que la representa; por otro, la figura de Librada se justifica no solamente por la iconografía martirial, sino también por la presencia de las otras imágenes, que justifican a esta santa concreta crucificada y no una distinta. Las esculturas que corresponderían a sus hermanas también muestran los símbolos del martirio por degollación en sus cuellos, como narra la hagiografía clásica del ciclo a la que hemos aludido. No tendría sentido descontextualizar a cada una de ellas y no intentar trazar una lectura unitaria de todas las imágenes situadas en un espacio tan concreto. No obstante, en la explicación anotamos la ausencia de una de las hermanas. Uno de los principales motivos de esta falta sería la disponibilidad de espacio en el tambor, que no dejó posibilidad de incluir otra imagen más.

Atendiendo al significado iconológico general que intentan transmitir el resto de los estucos del crucero y la iconografía del retablo, localizamos un mensaje de fortaleza y fe en Cristo, una apología de la esperanza. Las santas escogidas fueron paradigma de la fortaleza en la fe, como puede apreciarse a través de sus hagiografías. La construcción

${ }^{49}$ I. MATEOS GÓMEZ, A. LÓPEZ-YARTO ELIZALDE y J. M. PRADOS GARCÍA, El arte de la orden jerónima. Historia y mecenazgo, Madrid, 1999, p. 132. 
de esta nueva parroquia a comienzos del siglo XVIII, sometiéndose al patrocinio de la Virgen de la Esperanza, buscaría amparar a sus gentes con un mensaje catequético de convicción y confianza. El nuevo templo vendría a sustituir el espacio tradicional de la religiosidad del municipio puesto que la anterior parroquia se hallaba en lo alto de la fortaleza que dominaba la villa. En este marco constructivo y decorativo surgió un debate estético que criticó el uso de estas imágenes en un espacio y ámbito geográfico descontextualizado.

No obstante, mientras no aparezcan pruebas documentales que evidencien la presencia de estas figuras vinculadas a una determinada advocación se debe proceder a una comprensión rigurosa y en conjunto de los elementos visibles. A falta de esta información específica que justifique las correctas identidades, el análisis que ofrecemos demuestra su coherencia y es aceptable; ciñéndonos al estudio iconográfico que se ha programado hallamos una gran similitud con un grupo de arraigado culto seguntino, cuyas ramificaciones se pueden apreciar en otros espacios de la Península Ibérica como Galicia o Portugal. Si bien es cierto que encontramos diversas imágenes de Santa Librada en focos variados del territorio español, sirviéndonos de ejemplo la talla de la capilla de San Hermegildo de la Catedral de Sevilla o la tabla en la que aparece pintada en la Catedral de Santo Domingo de la Calzada, en el sureste peninsular el culto a la santa no abundó, ni mucho menos su representación en conjunto con sus otras hermanas. Por ahora, se ofrece esta revisión con el objetivo de reabrir el debate sobre el culto de esta santa y dar a conocer un magnífico ejemplo artístico poco conocido del tardobarroco español en tierras albaceteñas.

\section{BIBLIOGRAFÍA}

ANGULO ÍNIIGUEZ, D., La mitología y el arte español del Renacimiento, Madrid, 1952.
ÁVILA, A., Imágenes y símbolos en la arquitectura pintada española (1470-1560), Barcelona, 1993.

BASSEGODA I HUGAS, B., "Observaciones sobre el Arte de la Pintura de Francisco Pacheco como tratado de iconografía", Cuadernos de arte e iconografía, T. II, no 3, 1989, pp. 185-196.

BELDA NAVARRO, C. y HERNÁNDEZ ALBALADEJO, E., Arte en la región de Murcia: de la Reconquista a la Ilustración, Murcia, 2006.

BORNAY, E., Mujeres de la Biblia en la pintura del Barroco, Madrid, 1998.

CARMONA MUELA, J., Iconografía de los santos, Madrid, 2011.

CHEVALIER, J. y GHEERBRANT, A., Diccionario de los símbolos, Barcelona, 1986.

CIRLOT, J. E., Diccionario de símbolos, Madrid, 1997.

DÍAZ TENA, M. E., “La vida de Santa Librada y su fuente medieval", Culturas Populares. Revista Electrónica (en línea), nº 8, 2009, consultado el 25 de febrero de 2017. URL: http://dspace.uah.es/dspace/handle/10017/19820?locale-attribute $=$ es

FERRANDO ROIG, J., Iconografía de los santos, Barcelona, 1991.

GALLEGO, A., Historia del grabado en España, Madrid, 1979.

GARCÍA GUAL, C., Introducción a la mitología griega, Madrid, 2013.

GARCÍA MAHÍQUES, R., Iconografía e iconología. Volumen 1: la Historia del Arte como Historia Cultural, Madrid, 2008.

GARCÍA-SAÚCO BELÉNDEZ, L. G., “El retablo mayor de Santa María de la Esperanza de Peñas de San Pedro", Al-Basit: Revista de estudios albacetenses, no 9, 1981, pp. 141-161.

GOMBRICH, E. H., La evidencia de las imágenes, Vitoria-Gasteiz, 2016. 
GONZÁLEZ CHANTOS Y ULLAURI, D. E., Santa Librada. Virgen y mártir, patrona de la Santa Iglesia, ciudad y obispado de Sigüenza, Madrid, 1806.

GONZÁLEZ TORNEL, P., "El ornamento arquitectónico como base del cambio de gusto en la Valencia de mediados del siglo XVIII. De los estucos de la parroquia de San Andrés a los modelos académicos de Vicente Gascó en la capilla del Carmen", Ars Longa, no 20, 2011, pp. 97-108.

HALL, J., Diccionario de temas y símbolos artísticos, Madrid, 1987.

HERNÁNDEZ ALBADALEJO, E., "Belluga y el mecenazgo eclesiástico", en BELDA NAVARRO, C. (dir.) y GÓMEZ DE RUEDA, J. (coord.), Luis Belluga y Moncada: la dignidad de la púrpura, Murcia, 2006, pp. 83-85.

KRAPPE, A. H., "The Bearded Venus", Folklore, no 56, 1945, pp. 325-335.

MARTÍNEZ GÓMEZ-GORDO, J. A., "Santa Librada, virgen y mártir (revisión de su hagiografía, iconografía y culto)", Anales seguntinos, $\mathrm{n}^{\circ} 12,1996$, pp. 7-90.

MATEOS GÓMEZ, I., LÓPEZ-YARTO ELIZALDE, A. y PRADOS GARCÍA, J. M., El arte de la orden jerónima. Historia y mecenazgo, Madrid, 1999.

MAUQUOY-HENDRICX, M., Les stampes des Wierix conserves au cabinet des stampes de la Bibliotheque Royale Albert I ${ }^{\circ}$, Bruselas, 1978.

MONTES SERRANO, C., "Et in Arcadia Ego. Panofsky en perspectiva", $R A$ : revista de arquitectura, $\mathrm{n}^{\mathrm{o}}$ 9, 2007, pp. 29-42.

PANOFSKY, E., El significado de las artes visuales, Madrid, 1983.

PANOFSKY, E., Estudios sobre iconología, Madrid, 2008.

PEÑA VELASCO, C., El retablo barroco en la antigua diócesis de Cartagena. 1670-1785, Murcia, 1992.
PÉREZ-VILLAMIL, M., La catedral de Sigüen$z a$, Madrid, 1899.

PONZ, A., Viage de España, o Cartas en que se da noticia de las cosas más apreciables y dignas de saberse, que hay en ella, Madrid, 1788.

PORREÑO, B., Discurso de la vida y martirio de la gloriosa virgen y mártir Santa Librada, Cuenca, 1629.

PORTÚS PÉREZ, J., “Tratados de pintura y tratados de imágenes sagradas en la España del Siglo de Oro", en RIELLO, J. (ed.), Sacar de la sombra lumbre... La teoría de la pintura en el Siglo de Oro (1560-1724), Madrid, 2012, pp. 21-31.

RÉAU, L., Iconografía del arte cristiano. Iconografía de los santos: de la $G$ a la $O$, Barcelona, 1997.

RÉAU, L., Iconografía del arte cristiano. Iconografía de los santos: de la P a la Z, Barcelona, 1998.

RIVAS CARMONA, J., "Las iglesias barrocas de la ciudad de Murcia: consideraciones sobre su significación y arquitectura", Imafronte, no 19-20, 2007-2008, pp. 395-410.

RODRÍGUEZ G. DE CEBALLOS, A., “Fuentes iconográficas y literarias del cuadro de Velázquez Cristo y el alma cristiana", Cuadernos de Arte e Iconografía, no 8, 1991, pp. 82-90.

SÁNCHEZ FERRER, J., "El camarín de la Virgen de la Esperanza en las Peñas de San Pedro", Al-Basit. Revista de estudios albacetenses, $\mathrm{n}^{\circ}$ 54, 2009, pp. 59-78.

SÁNCHEZ FERRER, J., “Iconografía de los relieves de estuco de la Iglesia de la Esperanza de Peñas de San Pedro", Cultural Albacete, $\mathrm{n}^{\mathrm{o}}$ 8, 2007, pp. 9-15.

SÁNCHEZ MORENO, J., “Notas sobre arquitectos en Murcia, y noticia del escultor Pedro Federico", Anales de la Universidad de Murcia, 1945-1946, pp. 351-355. 
SLATKES, L. J., "Hyeronymus Bosch and Italy", The Art Bulletin, no 57/3, 1975, pp. 335-345.

URREA FERNÁNDEZ, J., "Revisión a la vida y obra de Luis Salvador Carmona", Boletín del Seminario de Estudios de Arte y Arqueología, no 49, 1983, pp. 441-454.

URREA FERNÁNDEZ, J., "Santa Eulalia”, en M. ARIAS MARTÍNEZ (coord.), Teso- ros del Museo Nacional de Escultura "Catálogo de la exposición", Zaragoza, 2005, pp. 151-152.

VEGA, P., Flos sanctorum, Sevilla, 1580.

VILLEGAS, A., Flos sanctorum y Historia general de la vida y hechos de Iesuchristo, Madrid, 1588. 